\title{
Tribunal Regional do Trabalho
}

\section{RECURSO ORDINÁRIO}

N.? TRT 1.700-58

Incompetência da Justiça do Trabalho nos casos da Estrada de Fetro Leopoldina.

A Rêde Ferroviária Federal S. A. Enquanto não se organizar a sociedade de economia mista, a ser constituida com o acërvo das atuais emprêsas ferroviárias da União de que trata a Lei n. 3.115 , de 16 de março de 1957, os servidores dessas entidades são funcionátios vinculados ao Ministério da Viação e Obras Ptiblicas, estranhos à jurisdição dos Tribunais do Trabalho.

Advogado do Recorrente: Hugo SEveTIANO RIBEIRO. MÃO.

Advogado do Recorrido: Cupertino Gus-

Vistos, relatados e discutidos êstes autos de recurso ordinário, entre partes, como $\mathrm{Re}$ corrente a Rêde Ferroviária Federal S. A. (Estrada de Ferro Leopoldina), e, como Recorridos: Roberto da Silva Medeiros, acordam os Juizes do Tribunal Regional do Trabalho da Primeira Região, por maioria, em acolher a preliminar de incompetência intuitu personnae, suscitada pela Recorrente pelos seguintes fundamentos: «Lê-se no Diário da Justiça de 18 de novembro de 1955 , à pág. 4,040, o V. Acórdão do Egrégio Tribunal Superior do Trabalho, proferido no processo número 3.674-54 em que uma das partes era exatamente a ora Recorrida, Estrada de Ferro Leopoldina, o seguinte: «Voto - Conheço do recurso e vou dar pela incompetência da Justiça do Trabalho decretando-a ex-officio. A sentença da Junta é de novembro de 1953. Ora, já estava em vigor a Lei n.? 1.890 , que data de junho, portanto já não mais competente era esta Justiça para dirimir a controvérsia. Conheço, pois, do recurso, preliminarmente, e no mérito decreto ex-officio a incompetência da Justiça do Trabalho. Isto pôsto, acordam os Juizes da $2 .^{*}$ Câmara do Tribunal Superior do Trabalho, unânimemente, conhecer do recurso e cassando a decisão re. corrida, decretar ex-officio a incompetência da Justiça do Trabalho para apreciar o feito. $\rightarrow$ Rio de Janeiro, 11 de junho de 1955». E no mesmo sentido decidiu o mesmo Egrégio Tribunal Superior nos recursos ns. 7.615-53 e 994-54, respectivamente dos recorrentes Silvio Vieira Cavalcanti e Waldir Ferreira contra a mesma Estrada de Ferro Leopoldina, bem como nos recursos ns. 359-54, 3.674-54, $3.749-55,7.034-55,1.258-55,1.072-55$, e 3.201-52. E temos ainda a homologação dessa jurisprudência pelo Excelso Pretório, - Supremo Tribunal Federal nos Conflitos de Jurisdição ns. $2.087,2.114,2.123,2.089$. 2.017 e 2.190 , sendo dêste relator o Ministro Orosimbo Nonato, e no Agravo de Instrumento n. ${ }^{?}$ 16.897, julgado em sessão de 17 de agôsto de 1954, proclamando sempre a competência especial de Juizes dos Feitos da Fazenda Pública para processar e julgar as causas em que são interessadas a União $\mathrm{Fe}$ deral ou as suas autarquias, inclusive quando se demanda com fundamento nos dispositivos das leis trabalhistas. Há dois equivocos em que laboram, data venia os que insistem em ainda considerar competente a Justiça do Trabalho para essa espécie apesar das Leis números 1.390 e 2.193. O primeiro é enxergar nas Leis ns. 1.890 e 2.193, um conceito que elas não têm: de só serem elas aplicáveis aos empregados admitidos após a sua vigência. Mostramos acima que, dispondo essas leis sôbre competência, são de Direito Público imediatamente aplicáveis, contra as quais não há direito adquirido a ser alegado, só podendo existir êste $\mathrm{em}$ direito substantivo e não $\mathrm{em}$ direito formal, ou do processo. O referido conceito é especifico do Decreto-lei n ${ }^{*} 8.249$, de 23 de novembro de 1945 que o consagrou expressamente. Mas os novos diplomas legais notadamente a Lei número 2.193, de março de 1954, que, não só não repetiu o conceito, como consignou expressamente a sua repulsa. Porque, além de dispor em sentido oposto, não se limitou a dizer «revogam-se as disposições em contrário» mas, para maior clareza e maior fôrça de expressão, usou de uma 
redundância, determinando no seu art. $8 .^{\circ}$ «Revogadas as disposições em contrário e, especialmente o Decreto-lei n. ${ }^{\circ} 8.249$, de 29 de novembro de 1945, esta Lei entrará em vigor à data de sua publicação». (Os grifos são nossos). Já que a Lei n.? 1.890 , de 13 de junho de 1953, deslocando no seu art. 2 . $^{\circ}$ da Justiça do Trabalho para a Justiça Comum a competência para essas ações, havia tevogado tòdas as disposições em contrátio, entre as quais estava indiscutivelmente o referido Decreto-lei $n .^{\circ} 8.249$, de 1045 ; mas a Lci seguinte a citada Lei n. 2.193 , de 1954, veio, como se mostra acima, confirmar, esclarecer, dissipar quaisquer dúvidas, no seu citado artigo 8. . A Recorrida Estrada de Ferro Leopoldina está hoje definitivamente incorporada ao Patrimônio Nacional. E' uma autarquia da União em forma de emprêsa. Ėstão os seus empregados amparados pela Legislação Social? Sustenta-se que sim, por dois motivos: 1.9 , porque já o estavam antes da incorporação da emprêsa ao Patrimônio Nacional e haveria então direito adquirido por se tratar de direito substantivo: $2{ }^{\circ}$, porque as duas leis acima mencionadas expressamente o reconhecem, mas na modalidade em que o fizeram. Mas reconhecendo-lhes direitos trabalhistas de caráter substantivo, a Lei número 1.890, de 13 de junho de 1955 , deslocou em seu art. 2. de iurtisdição da Justiça do Trabalho para a, Justiça Contum a apreciação dêsses direitos, atribuindo a esta exclusiva competência. E tão a fundo fêz que, na maioria de scus 22 artigos, do $3 .^{\circ}$ ao 19. dita $^{\circ}$ o rito processual a ser seguido. Podia fazêlo? E por que o fêz? A $1 .^{7}$ pergunta tem respondido iterativamente o Supremo Tribunal Federal, o intérprete máximo da Constituição, proclamando a perfeita constitucionalidade do art, $2 .^{\circ}$ da referida Lei n. ${ }^{\circ} 1.390$. Mas porque o fềz o legislador: Para resguardar os interêsses da Administração. Proclamou o Supremo Tribunal Federal, no resguardo dos interêsses da União, «o que menos importa é o objeto especifico da ação, seja de fundo trabalhista ou não», para definir a competência da Vara da Fazenda Pública. (O Direito, ano XIII, vol. 65, pág. 133). Visou - legislador, com essa lei entregar a órgãos judiciários mais severos a proteção de interêsse público, nos litigios trabalhistas dêsses empregados, que, na verdade, prestam seus serviços atendendo a necessidades públicas $e$ não a emprêsas de atividades privadas, que visam fins particulares. Visou a lei uma maior defesa da disciplina, da produção, da eficiên. cia do trabalho. Di-lo claramente o $\$ 2 .^{\circ}$ do art. 1. ${ }^{\circ}$ in verbis: «Entre os atos de indis- ciplina ou insubordinação a que se refere o art. 482, alinea $h$ da Consolidação das Leis do Trabalho, incluam-se, no tocante aos seus empregados declarados no presente artigo, inci- tar, promover, tomar parte ou fazer propaganda de greve de qualquer natureza e finalidade, bem como pertencer a partido politico, associação, clube ou grupo, etc., proibido como nocivo à ordem social ou politica». Mas os órgãos judiciários atualmente competentes para apreciarem os litígios dêsses empregados, terão necessàriamente de resolver se ainda estão êles amparados pela legislação trabalhista. O ilustre Ministro Delfim Moreira julgando o dissidio coletivo de natureza juridica ajuizado originàriamente no Tribural Superior do Trabalho, contra esta mesma Estrada de Ferro Leopoldina pelo Sindicato de seus empregados assim se expressou quanto à situação juridica dêsses empregados: «... esta relação de direito público determina-se pelo nivelamento da situação das partes, das quais é o Estado ou qualquer entidade de poder público, atuando como ente soberano. Os empregados que servem a essas entidades para a satisfação de interêsses e de necessidade da coletividade, transportam para o direto público os vínculos qu? os unem. Foi por isso que o Decreto do Poder Executivo número 31.078 , de 3 de julho de 1952 , que dispôs em caráter provisório sôbre, a administração da Estrada de Ferro Leopoldina, possibilitou no parágrafo único do art. $3 .^{\circ}$ ao Ministro da Viação e Obras Públicas, por proposta do Administrador da Estrada, a introdução nos regulamentos vigentes de modificações necessárias ao bom funcionamento dos serviços e que se harmonizam com a legislação de caráter geral existente ao caso. Foi ainda pelo mesmo motivo que a Lei $n .^{\circ} 1.765$, de 18 de dezembro de 1952, que concedeu um abono de emergência aos servidores civis do Poder Executivo, o estendeu aos servidores da Estrada de Ferro Leopoldina (artigo 20 letra a), os quais foram ainda contemplados com outro abono, o estabelecido na Lei n.? 2.412, de 1 de janeiro de 1955. Demonstração clara de que o Estado os equiparou, para o efeito de percepçăo dos abonos de emergência e especial temporário, aos servidores civis do Poder Público. «E tão lógico foi no seu voto que reconheceu até a incompetência da Justiça do Trabalho para conhecer (até) de dissidios coletivos para fixação de salários dos servidores da Estrada da Ferro Leopoldina, matéria que sòmente poderá ser resolvida por via de lei, de decreto do Poder Executivo, ou, ainda, perante a Justiça Comum, no fçro privativo da União se porventura algum direto estiver postergado $\gg$. Na verdade, o art. $10^{\circ}$ da citada Lei n. ${ }^{\circ} 1.890$ só reconhece com direito as garantias substantivas da Legislação trabalhista nos empregados das emprêsas que menciona, e entre elas das entidades autârquicas, como o é a Recorrida, que não gozarem de garantias especiais. E são essas garantias especiais, de ahonos dos servidores 
públicos, de salário-familia, de adicionais, a maioria, enfim, dos beneficios de que gozam os funcionários civis da União, que os excluem atualmente da própria legislação social substantiva, seguindo, aliás, o critério do artigo 7.? alinea $d$, da Constituição das Leis do Trabalho que já excluia os que estivessem em. situação análoga à dos funcionários públicos. E note-se que o texto diz análoga e não idêntica. E a Lei n. ${ }^{\circ} 1.890$ precisou o conceito, na expressão garantias especiais não consignando a idéia de stôdas as garantias dos funcionários públicos». São garantias especiais de que se beneficiam os empregados das atividades privadas, garantias essas outorgadas por várias leis aos servidores das emprêsas incorporadas ao Patrimônio da União e, entre elas, a Estrada de Ferro Leopoldina. Alteada, protegida pelo Poder Público em nivel privilegiado, a situação dêsses empregados transmudou-se em sua essência, «transportando para o direito público», no dizer arguto do Ministro Delfim Moreira, acima citado. os vinculos que os unem. Além das leis citadas e outras, é decisiva a Lei n. ${ }^{\circ} 1.711$, de 28 de outubro de 1932 (Estatuto dos Funcionários Públicos Civis) que, no art. 252 n. ${ }^{\circ}$ II, estendeu o seu regime juridico aos servidores autárquicos. Acresce ainda que a Recorrente, Estrada de Ferro Leopoldina, é de há muito de propriedade exclusiva da União. E posteriormente passou a integrar à Rêde Ferroviária Federal, a ser constituida em sociedade anônima. E' inteiramente procedente o comentário do ilustre tratadista, o Procurador Joâo Antero de Carvalho publicado no «O Jornal» de 21 de novembro dêste ano, do seguinte teor: - «Sufragando o parecer do ilustre Procurador Geral da República, o Colendo Supremo Tribunal Federal decidiu recentemente que, aplicada a Lei n. ${ }^{\circ} 1.890$, de 23 de junho de 1953 , reiteradamente considera constitucional o julgamento das reclamações trabalhistas previstas nos seus artigos $10^{\circ}$ e $20^{\circ}$ são, efetivamente, de competência dos Juizes da Justiça Comum, funcionando como Juizes dos feitos da Fazenda Pública. Todavia, aduziu, uma vez que a referida lei não estatuiu quanto ao 'Tribunal competente para julgamento dos recursos cabiveis terão de funcionar naqueles feitos, como segunda instância, os tribunais Regionais do Trabalho. $\mathrm{O}$ pretório Excelso, data venia, não atendeu ao disposto na Constituição Federal, que no artigo 104, II, atribui competência ao Tribunal Federal de Recursos para julgar, em grau de recurso, as causas decididas em primeira instância, quando a União fôr interessada como autora, ou ré, assistente ou opoente. De fato que, em se tratando de emprêsa de propriedade da União e por esta diretamente administrada, parece fora de dúvida que 0 aspecto essencial da matéria entende primor- dialmente com a aplicação dos artigos 201 e 104, a, da Constituição. No caso de litigios entre a E. F. Leopoldina e seus empregados - Ministro Edgard de Oliveira Lima, do Tribunal Superior do Trabalho, tem proferido votos nesse sentido. Salientou que se trata de um próprio exclusivamente da União, não é uma autarquia, não tem personalidade jurídica própria. As reclamações, contra ela ajuizadas, são ações diretamente contra a União; a condenação porventura resultante, é contra a Ulnião; e sòmente como tal poderá ser executada. Reproduziu conceito da recente obra de Alcino Pinto Falcão e José Aguiar Dias - «Constituição Anotada》 1956, vol. I, pág. 200, verbis: «Nem tôda a matéria trabalhista é da competência dessa Justiça; o $\$ 10^{\circ}$ do art. 123 , ressalva os acidentes do trabalho, que cabem à Justiça ordinária. A esta também compete conhecer uma outra espécie: quando a União fôr parte interessada, caso em que o litigio será decidido no Juizo privativo da Fazenda Pública». A Recorrente é emprêsa incorporada. Recentemente, em face da Lei n." 3.115, de 16-3-57, seu acervo passou à aclministração direta da União, até passar a constituir o patrimônio de uma sociedade de economia mista. O Decreto número 42.385 , de $30-9-57$, dispõe serem da responsabilidade exclusiva da União as obrigações resultantes de ações ajuizadas, ou por ajuizar, seja qual fôr o estado em que se encontrem. «Enquanto não se organizar disse-o o emérito Juiz Pires Chaves na assentada de julgamento do recurso $n .^{\circ} 140$, de 1947. - a sociedade de economia mista, ou melhor, enquanto a União Federal fôr a única acionista de uma sociedade que ainda não se constituiu inclusive porque a lei das sociedades anônimas exige, no minimo, o coeficiente de sete acionistas, o regime juridico que disciplina os servidores da Leopoldina é, sem dúvida, o reconhecido aos funcionários da União porque, desde então, vinculadas ao Ministério da Viação e Obras Públicas. Nesse sentido, aliás, o Chefe do Executivo, em obediência ao disposto no art. $16, \S 2 .^{\circ}$ alínea a, daquele diploma, veio de baixar o Decreto n. 43.102 , de 21 de janeiro de 1953, dispondo que o pessoal das emprêsas ferroviárias passam a constituir quadros e tabelas suplementares na jurisdição do Ministério da Viação $O$ pessoal excedente do quadro da nova entidade, nos têrmos do art. $8 .^{\circ}$ do mesmo Decreto número 43.102, será distribuido em outros órgãos subordinados àquele Ministério. Nessas condições. é indiscutivel a incompetência da Justica do Trabalho ex-vi do art. $7 .^{\circ}$, letra $c$, da Consolidação». É, pois, a Justiça do Trabalho manifestamente incompetente para apreciar e decidir o presente litigio. Encaminhem-se os autos ao Juizo dos Feitos da Fazenda Pública. - Rio de Janeiro, 12 de novembro de 1958. 
- Gustavo CÂmara Simốes Barbosa, Juiz no exercício da Presidência. - PıO Benedito Ottoni, Relator. - Ciente. - Carlos MenDES PIMENTfl, Procurador Regional Substituto.

(Publicádo no Diário da Justiça de 6 de fevereiro de 1959 - páginas ns. 416-17 apenso ao $\mathrm{n} \cdot{ }^{\cdot} 31$ ).

\section{RECURSO ORDINÁRIO N.? TRT. 1.105-58}

Competência da Justiça especializada para julgat reclamações formuladas por empregados da Réde Ferroviária S.A. (Estrada de Ferro Leopoldina).

Vistos, relatados e discutidos os presentes autos de recurso ordinário, sendo recorrente Osiris Figueira da Silva e recorrida Rêde Ferroviária Federal S.A. (Estrada de Ferro Leopoldina). A MM. 12 Junta julgou incompetente a Justiça do Trabalho para apreciar a presente reclamação. Daí o recurso interposto pelo empregado. A emprêsa contraarrazoou e a douta Procuradoria opina pelo provimento do apêlo. É o relatório. Voto: Adoto os fundramentos do parecer de fls. 21-22, que fica fazendo parte integrante dêste voto: «O voto magnifič do ilustre Ministro Oscar Saraiva, proferido no processo n. ${ }^{\circ} 1.854-56$, é irrespondivel e, parece-nos, resolve, plenamente a questão debatida nestes autos: competência desta Justiça especializada para julgar reclamações formuladas por empregados da Estrada de Ferro Leopoldina ora parte integrante da sociedade anônima mista, Rêde Ferroviária Federal S.A., instituida pela Lei n. ${ }^{\circ} 3.115$ de 16 de março de 1957 . Julgando o proces̀so acima referido, assim entendeu aquêle douto Ministro, seguido, aliás pela maioria do Tribunal:

«Tal discussão, contudo já perdeu sua razão de ser com a promulgação da lei n. ${ }^{\circ} 3.115$, de 16 de março de 1957, que instituiu, como sociedade anônima de economia mista, a Rêde Ferroviária Federal S.A., incorporando à mesma tôdas as estradas de ferro de uma forma ou de outra pertencentes à União. Tal sociedade teve seus estatutos aprovados pelo Dečreto $\mathrm{n}^{\circ} 42.385$ de 30 de setembro de 1957 e, no próprio Diário Oficial em que foram os mesmos publicados, foi taumbém publicado o Decreto n. ${ }^{\circ} 42.380$ e, ainda de 30 de setembro de 1957, no qual foi determinado que todos os funcionários ou servidores de várias estradas ai enumeradas, inclusive da Estrada de Ferro Leopoldina, passavam para o serviço da Rêde Ferroviária Federal S.A., a partir dessa data. Desapareceu, dêsse modo, a razão de se pretender atribuir ao fôro privativo cáa União a competência para conhecer das demandas ajuízadas por empregado da Estrada de Ferro Leopoldina com a sua desvinculação do patrimônio nacional e sua passagem para patrimônio de sociedade anônima de economia mista, cuja personalidade de nenhum modo se confundo čom a da União Federal, e que não goza do privilégio de fôro, e nem poderia pretender a tal sem ofensa ao texto do art. 141, § 26 Constituição».

Conseqüentemente somos pelo conhecimento e provimento do apêlo, tempestivamente interposto, a fim de que, competente esta Justiça para dirimir a presente controvérsia, julgue a MM. - Junta o mérito desta reclamatória». Dou provimento ao recurso. Acordam os Juizes do Tribunal Regional do Trabalho da Primeira Região, pelo voto de desempate, dar provimento ao recurso para, julgando competente a Justiça do Trabalho para apreciar a ação mandar que a MM Junta aprecie o mérito.

Rio de Janeiro, 22 de setembro de 1958. - Amaro Barreto da Silva, Presidente. - João Batista de Almeida, Relator designado.

Ciente: Carlos Mendes Pimentel, Procurador Regional Substituto.

(Publicado no Diário da Justiça de 28-11 de 1958 apenso ao n. $271-$ p. n. $\left.{ }^{\circ} 4.185\right)$. 